\title{
Active Noise Control using Three Dimensional Beam Steering
}

\author{
$\bigcirc$ 皆川 健彦（首都大学東京） 正 田中 信雄（首都大学東京） \\ Takehiko MINAGAWA,Tokyo Metropolitan University,6-6 Asahigaoka,Hino-city,Tokyo
}

\begin{abstract}
This paper deals with active noise control (ANC) using phased array speaker as a secondary source. Liner phased array speaker produces high directivity sound beam which lean to another direction against sound axis in two-dimensional region. ANC using a liner phased array achieves high degree of flexibility pinpoint control. This paper expands the steering range of high directivity sound beam to three-dimensional area from two-dimensional area by using a matrix phased array speaker and suggests ANC for three-dimensional acoustic field. Matrix phased array speaker enables efficient ANC system in arbitrary point in three-dimensional area.
\end{abstract}

Key words : Active noise control, Beam steering, Phased array speaker

\section{A1.はじめに}

産業の発達に伴い増加の一途をたどる騒音問題に対し， アクティブノイズコントロール(ANC) という技術が注目 されている．騒音に対して同振幅逆位相の制御音を与える ことにより，音波の干渉により制御点の音圧を抑制する技 術である. 従来の研究では制御音源にボイスコイル型スピ 一カ用いられてきたが, 近年ではパラメトリックスピーカ やリニアフェイズドアレイスピーカなど, 指向性の高いス ピーカを制御音源に用いた ANCが考案され，ボイスコイ ル型スピーカを用いた手法と比べた場合, 制御点の周囲に おける音圧の上昇を抑えた A N Cが実現されている.

リニアフェイズドアレイスピーカとは, ホイヘンスの原 理に基づき, 音源面に対して傾いた角度を持つ擬似的波面 を形成させるフェイズドアレイという技術を忍用し，スピ 一カの音軸に対して二次元方向の任意の角度に向けて強い 指向性を舵取りすることができるという特徽がある.

本研究では指向性のステアリング可動域を二次元領域か ら三次元領域に拡大した，マトリックス型フェイズドアレ イスピーカを制御音源に用いた ANC を試みる.強い指向性 (ビ一ム)をもつ音波を三次元領域の任意の点に向け舵取り (ステアリング)することにより, より自由度の高い ANC が 可能になると期待される.

A2. マトリックスフェイズドアレイスピーカを用いた ANC

リニアフェイズドアレイにおいて舵取りされた指向性は, 同一直線上に等間隔で配列された素子に微小な遅延時間 $\Delta \tau$ を与えることにより得られるが, マトリックスフェイズ ドアレイでは, 音軸を $y$ 方向としたとき, $x$ 方向, $z$ 方向 にそれぞれ $\Delta \tau_{x}, \Delta \tau_{z}$ を与えることにより三次元領域の任 意の点に指向性を舵取りする. ここで, ボイスコイル型ス ピーカと, ステアリング角を $\theta_{s}=30^{\circ}, \phi_{s}=30^{\circ}$ としたマト リックスフェイズドアレイとをそれぞれ制御音源に用いた 場合のANCの比較をした場合, 制御点における音圧の抑 制は両者共に達成されているが，マトリックスフェイズド アレイを制御音源として用いた場合においては，周囲への 影響が小さいということが言える。

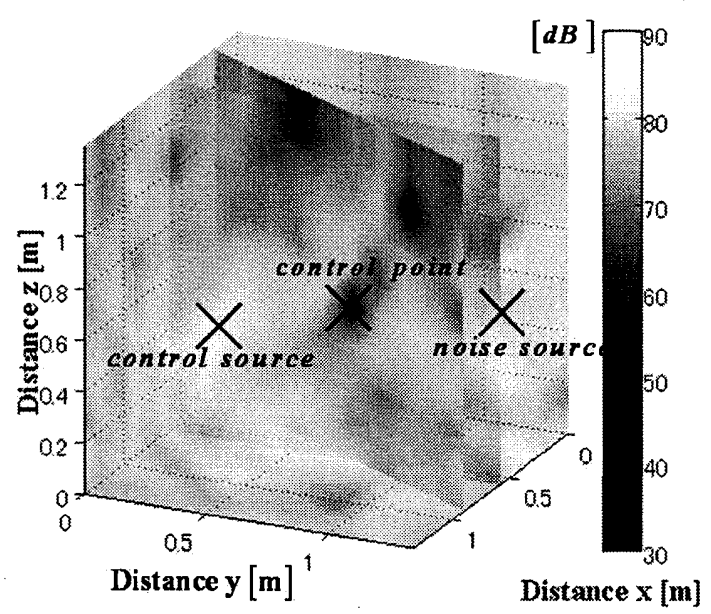

Fig.Al ANC using a voice-coil type speaker

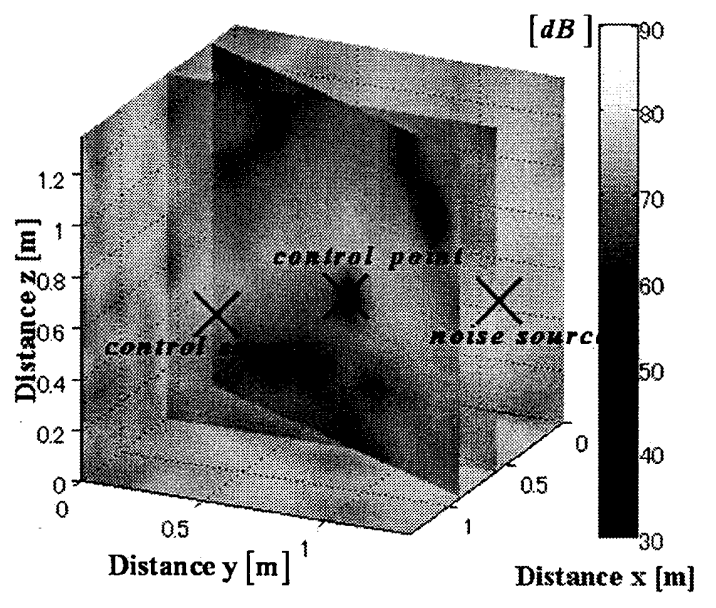

Fig.A2 ANC using a matrix phased array speaker

\section{A3. 結言}

（1）マトリックス状に配列されたフェイズドアレイスピー カのパラメータの最適な設計方法を明らかにした。

（2） 2 次元領域から 3 次元領域に拡大されたビームステア リングをANCに応用することで, 制御点の設定を選ばず, かつ周辺に与える影響が少ない, 高自由度・高効率の ANC システムが可能になる事を示した. 


\section{1.序論}

制御音により騒音を制御するアクティブノイズコントロ 一ル(ANC)の理論は古く, Lueg の特許(1)まで遡ることがで きる. ANC を実行するには精密な信号処理が必要なため, 当時のアナログ技術では制御効果に限界があったが，近年 の高性能で安価な DSP(Digital Signal Processor)の普及に より, ANC が静肃化の手法として用いられるようになった. ANC とは, 制御音源から放射される制御音により, センサ 箇所において騒音を抑制する技術である. ANCにおける問 題点は, 制御音源より放射される音が制御点以外にも伝播 してしまうため, 制御点において音圧の抑制をできても, それ以外の箇所においては音圧の増加を招いてしまうとい うことにある，加えて，ANC を適用するにあたり，ユーザ リティの観点よりフィードフォワード制御法を適用するこ とが多い.この場合, 制御音源を駆動する参照信号が必須 となるが, センサ出カとコヒーレンスの確実な騒音をマイ クロフォンより直接採取しようとすると, 制御音の混在に よりシステムが不安定化する懸念があり, ANC の実利的な 構築の妨げとなっている.

ここで，制御音に球面波でなく光のように指向性の高い 音波を用いた場合，上述の問題は解決される。すなわち， ターゲットとする制御点における音圧抑制を達成し，かつ 他所に影響を及ぼすことのない ANC が可能になる.さらに， 騒音が到来する箇所にマイクロフォンを設置しても，これ に制御音は進入しないので, 制御系の構築も簡素で安定し たものとなる. これを可能とするものがパラメトリックス ピーカ(PAL)である. PAL を用いた ANC の分野における これまでの研究として, 2005 年に Tan・田中(2) は PALを制 御音源とする ANC システム構築の可能性について論じて いる. 2008 年には小松崎ら (3)が実験的見地より PALによる 音圧抑制の可能性について論じており，田中・相原(4)が PAL を ANCに組み込んだ制御システムを構筑し，実験によりそ の有意性を示した.

しかし，PALを制御音源に用いた場合，その高い指向性 が裏目に出てしまう場合がある。これは，高い指向性を持 つが故に，スピーカの音軸上でしか制御ができないためで ある.したがって，スピーカの向きを変えることができな い場合, これは ANC システムとして死活問題と成り得る. これを補完する技術がフェイズドアレイである.フェイズ ドアレイは, 非破壊検査や医用超音波診断機器などに用い られている技術であり, 振動子を一列に幾つか並べ, 各素 子の位相を遅延させることにより, ホイヘンスの原理を利 用し, 音源面と異なる角度を持つ疑似的波面を形成するこ とができる．このフェイズドアレイをパラメトリックアレ イに適用することで, 超音波の波面の角度を電子的にステ アリングし，二次的に生じる差音の伝搬方向を変えること が可能となる. N.田中・M.田中ら(5)は, リニアフェイズド アレイをパラメトリックスピーカに適用し，ANCに用いる ことで二次元音場領域の任意の制御点の音圧低減を保証し、 かつ制御点以外の領域への影響が少ないシステムを実現し た.

本研究では指向性のステアリング可動域を二次元領域か ら三次元領域に拡大したマトリックスフェイズドアレイス ピーカを用いた ANC を試みる. 強い指向性(ビーム)をもつ 音波を三次元領域の任意の点に向け舵取り(ステアリング) することにより,より自由度の高い ANC が可能になると期 待される、

\section{2. 理論}

2.1 マトリックス型フェイズドアレイの設計

リニアフェイズドアレイにおいて舵取りされた指向性は,

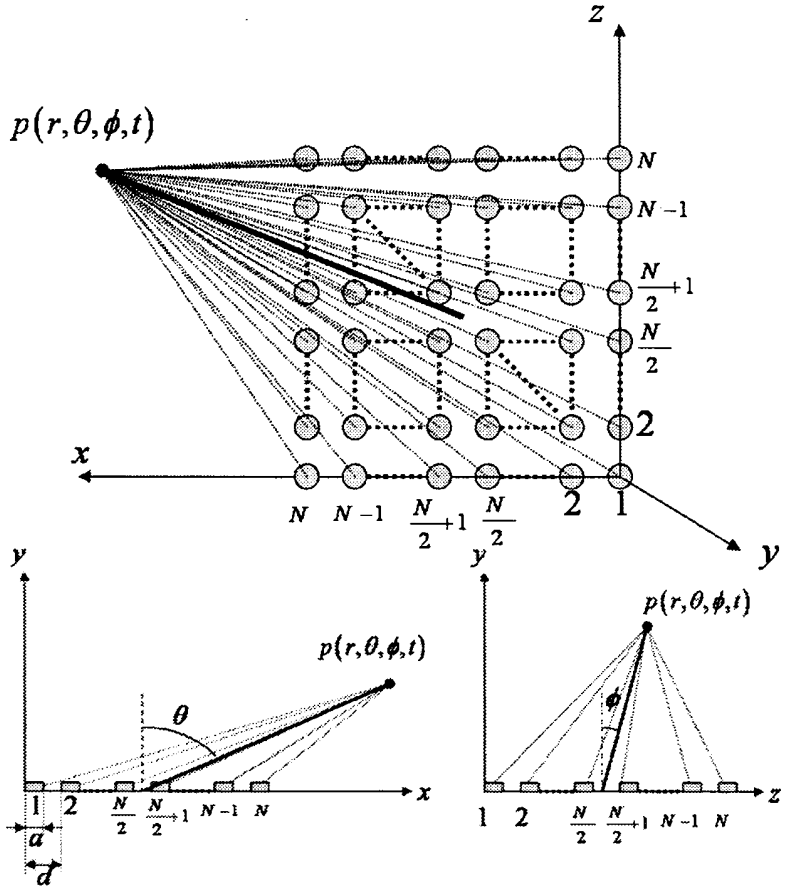

Fig.1 Geometry model of matrix phased array speaker

同一直線上に等間隔で配列された素子に微小な遅延時間 $\Delta \tau$ を与えることにより得られるが, マトリックスフェイズ ドアレイでは, 音軸を $y$ 方向としたとき, $x$ 方向, $z$ 方向 にそれぞれ $\Delta \tau_{x}, \Delta \tau_{z}$ を与えることにより三次元領域の任 意の点に指向性を舵取りできる. 開空間場において理想的 な点音源が発する音の音圧は式(1)で記述される.

$$
p(r, t)=\frac{j \omega \rho_{0} q}{4 \pi r} \cdot \exp \{j(\omega t-k r)\}
$$

一つの素子が無数の点音源から成ると仮定した上で, Fig.1 のようにマトリックス状に配列された素子に微小な遅延時 間 $\Delta \tau_{x} \Delta \tau_{z}$ を与えて励振させた時, 任意の点に及ぼす音圧 $p(r, \theta, \phi, t)$ は式(2)のように記述できる.

$$
\begin{aligned}
& P(r, \theta, \phi, t)=\sum_{i=1}^{N} \cdot \sum_{j=1}^{N} P_{i j} \\
& =\frac{j \omega \rho_{0} q}{4 \pi r} \cdot \exp \{j(\omega t-k r)\} \cdot a \operatorname{sinc}\left(\frac{k a \sin \theta}{2}\right) \\
& \times \exp \left(\frac{j k a \sin \theta}{2}\right) \frac{\sin \frac{N\left(\omega \Delta \tau_{x}-k d \sin \theta\right)}{2}}{\sin \frac{\omega \Delta \tau_{x}-k d \sin \theta}{2}} \\
& \times \exp \left\{-j\left(\frac{\omega \Delta \tau_{x}-k d \sin \theta}{2}\right)(N-1)\right\} \\
& \times a \operatorname{sinc}\left(\frac{k a \sin \phi}{2}\right) \cdot \exp \left(\frac{j k a \sin \phi}{2}\right) \\
& \sin \frac{N\left(\omega \Delta \tau_{z}-k d \sin \phi\right)}{2} \\
& \left.\left.\times \frac{\sin \frac{\omega \Delta \tau_{z}-k d \sin \phi}{2}}{2}\right)(N-1)\right\} \ldots \ldots . . . .
\end{aligned}
$$

ここで, $k=\omega / c$ : 波数, $c$ : 音速, $\omega$ :角周波数, $a$ : 素子幅, $d:$ 素子間隔, $N$ :素子数 である. 
また幾何学的関係より

$$
\begin{aligned}
& \theta_{s}=\sin ^{-1}\left(c \Delta \tau_{x} / d\right) \\
& \phi_{s}=\sin ^{-1}\left(c \Delta \tau_{z} / d\right)
\end{aligned}
$$

がステアリング角として与えられる.

次にリニアフェイズドアレイの指向性関数を角度 $\theta$ につ いて式(4)のように定義する.

$$
\begin{aligned}
D(\theta) & =\left|\frac{p(r, \theta, t)}{p\left(r, \theta_{s}, t\right)}\right| \\
& =\mid \frac{\operatorname{sinc}\left(\frac{k a \sin \theta}{2}\right)}{\operatorname{sinc}\left(\frac{k a \sin \theta_{s}}{2}\right)} \cdot \frac{\sin \frac{N \pi d\left(\sin \theta_{s}-\sin \theta\right)}{\lambda}}{N \sin \frac{\pi d\left(\sin \theta_{s}-\sin \theta\right)}{\lambda} \mid} .
\end{aligned}
$$

$D(\theta)$ は $\theta$ のみの関数で与えられ，装置の性能は振動子の パラメー夕 $a, d, N$ に依存する. $D(\theta)$ を最適に設計する ことにより，リニアフェイズドアレイスピーカの指向性が 向上される. $\phi$ についても式(4) と同様の指向性関数を用い て $D(\phi)$ の最適設計を行い, 最適設計された $D(\theta)$ および $D(\phi)$ を組み合わせを, マトリックスフェイズドアレイスピ 一力の指向性関数として設計に用いる.

Fig.2 は，ステアリング角を $30^{\circ}$ として， $-90^{\circ} \leq \theta \leq 90^{\circ}$ の 音場に生じた典型的な指向性を示す. 指向性関数における 最適な設計として,

$$
\begin{aligned}
& \text { ・メインローブの鋭利化 } \\
& \text { ・グレーティングローブの除去 } \\
& \text { ・サイドローブの抑制 }
\end{aligned}
$$

の 3 点を目標とする. 本論文では素子幅 $a$ が微小である事 を仮定し, 素子数 $N$, 素子間隔 $d$, に注目する. 式(4)の指 向性関数より, メインローブ幅を狭くし，かつグレーティ

$$
d \leq d_{\max }=\frac{\lambda}{1+\sin \left(\theta_{s}\right)_{\max }} \frac{N-1}{N} .
$$

ングローブを避けるには,

を与えることが有効である.ここで $d_{\max }$ はグレーティング ローブを生じない最大の素子間隔であり, $\left(\theta_{s}\right)_{\max }$ は最大ス

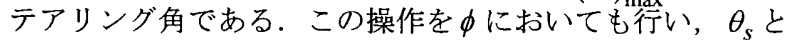
$\phi_{s}$ のうち稼動域の広い方の $d_{\max }$ をマトリックスフェイズ ドアレイスピーカの素子間隔として採用する．また $N$ を増 加させることでメインローブの鋭利化，サイドローブの抑 制が得られるが， $N$ の増加は同時に装置の複雑化，巨大化 を伴うため, $N=8 \sim 16$ に設定するのが妥当である.

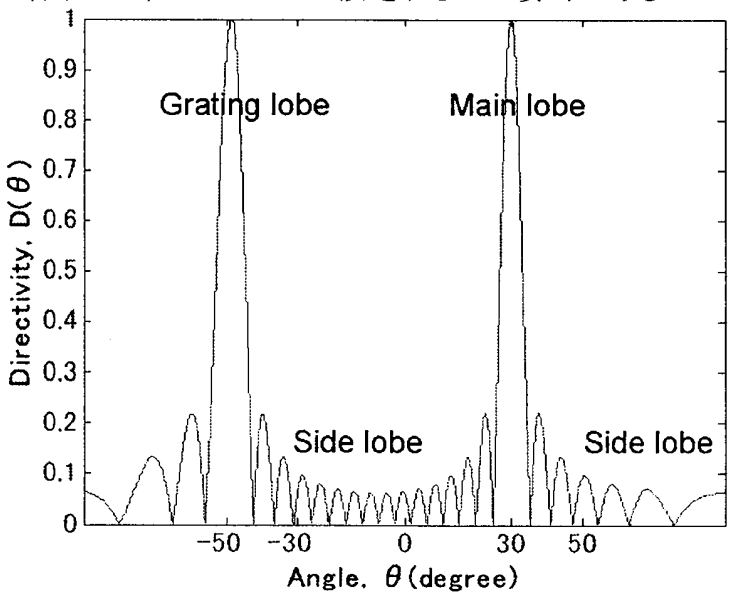

Fig.2 Directivity function of liner phased array speaker
3.3D ビームステアリングを用いた ANC の実験

\section{1 実験装置及び実験方法}

一般的なボイスコイル型スピーカと，指向性をステアリ ングさせた状態のマトリックスフェイズドアレイスピーカ の二種類の制御音源を用いて ANC の実験を行い結果を比 較した. $1250 \mathrm{~Hz}$ の騒音を対象とし，適応アルゴリズムには Filtered-x LMS を使用した。 マトリックスフェイズドアレ イスピーカは, $N=4 \times 4=16, d=d_{\max }$ として設計し，ス テアリング角を $\theta_{s}=30^{\circ} ， \phi_{s}=30^{\circ}$ とした. Fig.3-1 に実験 装置の配列図を示す. 測定する音場は $1.35 \mathrm{~m} \times 1.35 \mathrm{~m} \times 1.35 \mathrm{~m}$ の三次元空間とし $0.15 \mathrm{~m}$ 刻みでマイクロホントラバースを 用いて，騒音源のみの場合，ボイスコイル型スピーカを用 いた場合の A N C，マトリックスフェイズドアレイスピー 力を用いた場合の ANCにおいて音圧を計測し, 数值解析 と合わせて Fig.5〜Fig.10のように音圧分布を得た. 騒音源, 制御音源，及び制御点の位置関係を Fig.4に示す.

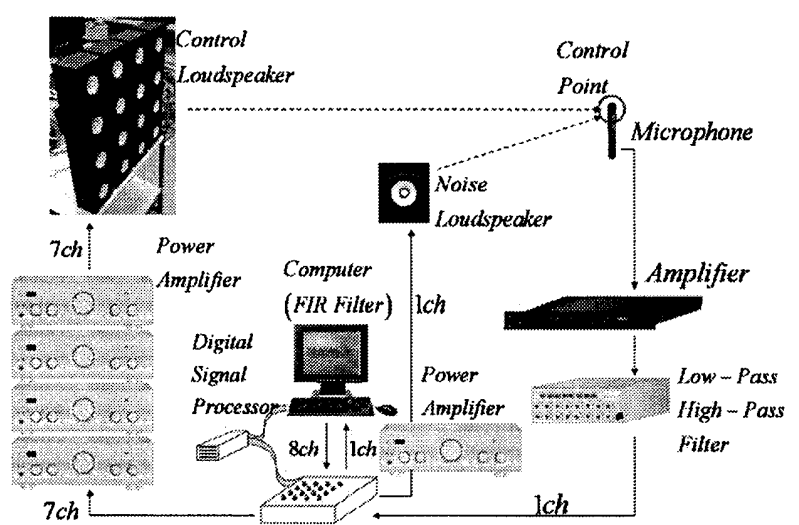

Fig.3 Schematic design of experimental setup

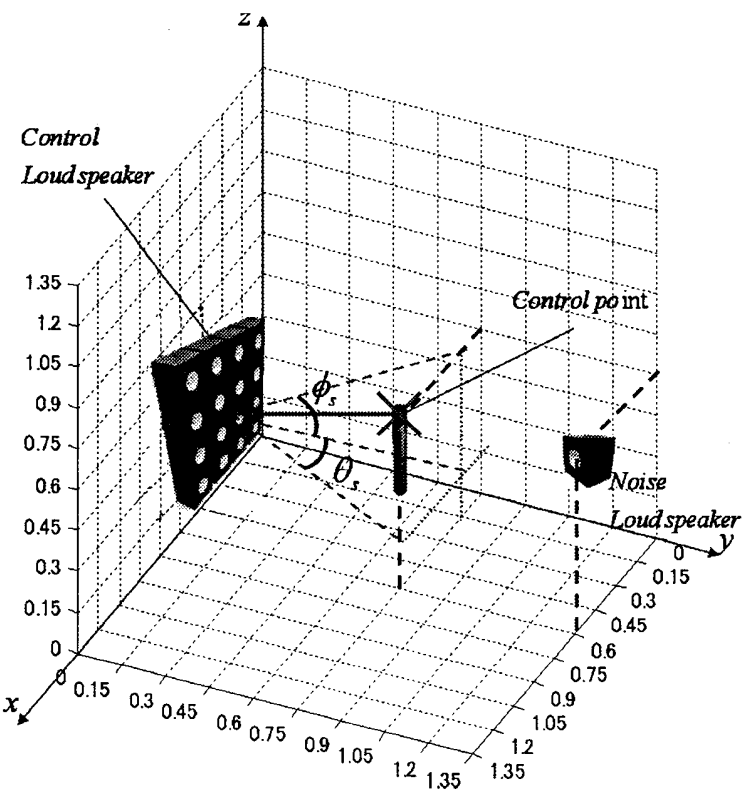

Fig.4 Schematic design of experimental arrangement of a microphone and speaker 


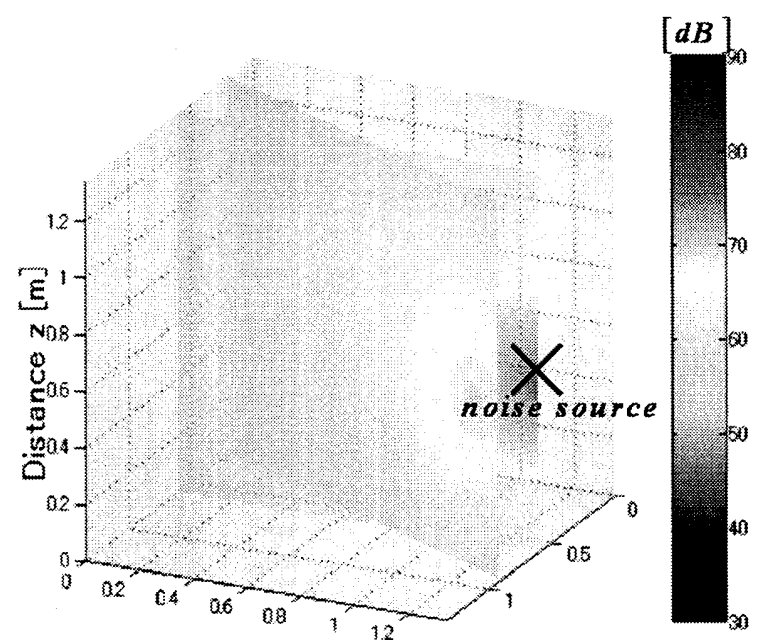

Distance $\times[\mathrm{m}]$

Fig.5 Numerical analysis of noise source acoustic pressure distribution

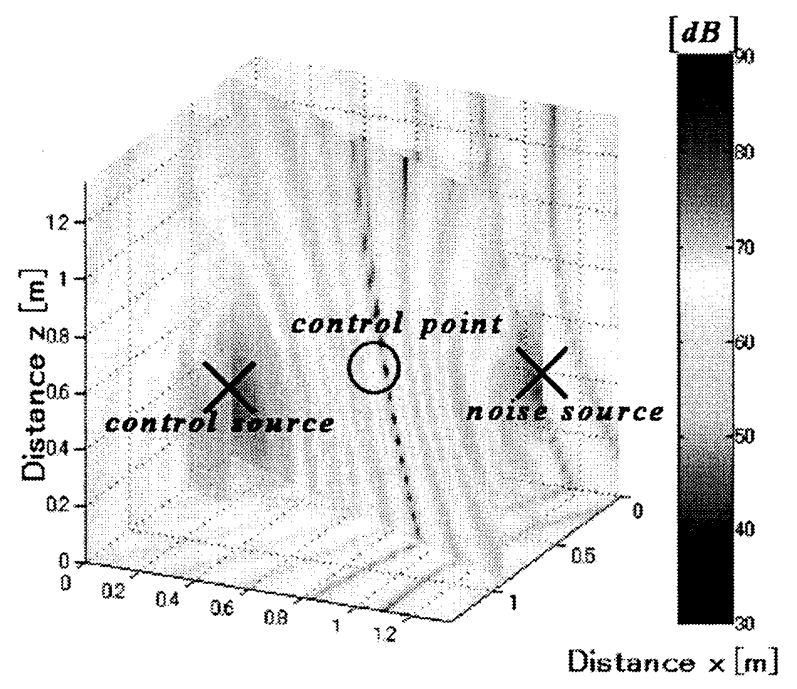

Fig.6 Numerical analysis of ANC using a voice-coil type speaker

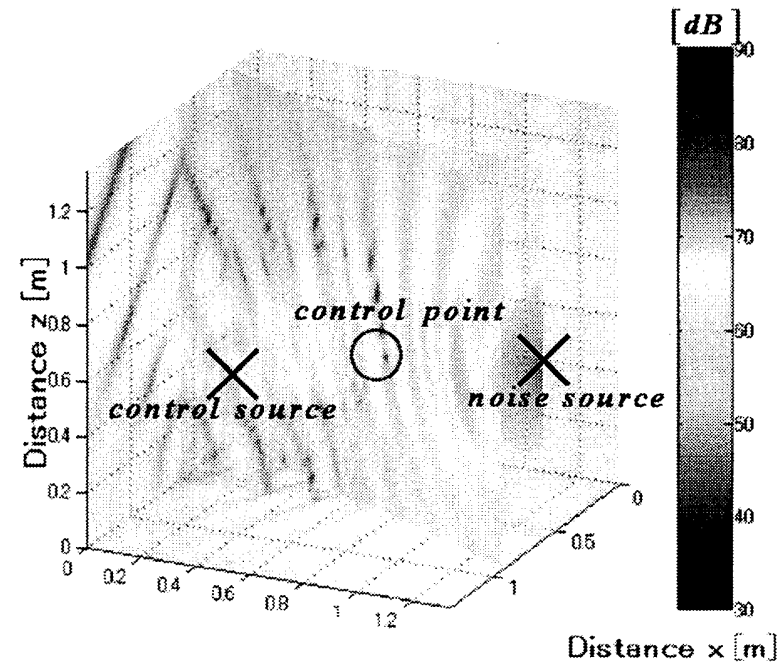

Fig.7 Numerical analysis of ANC using a matrix phased array speaker

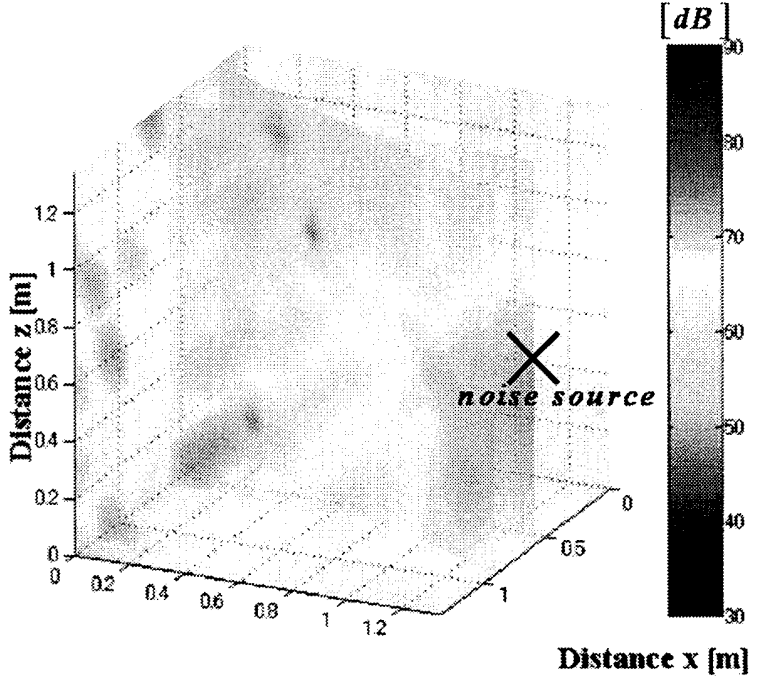

Fig. 8 Noise source acoustic pressure distribution

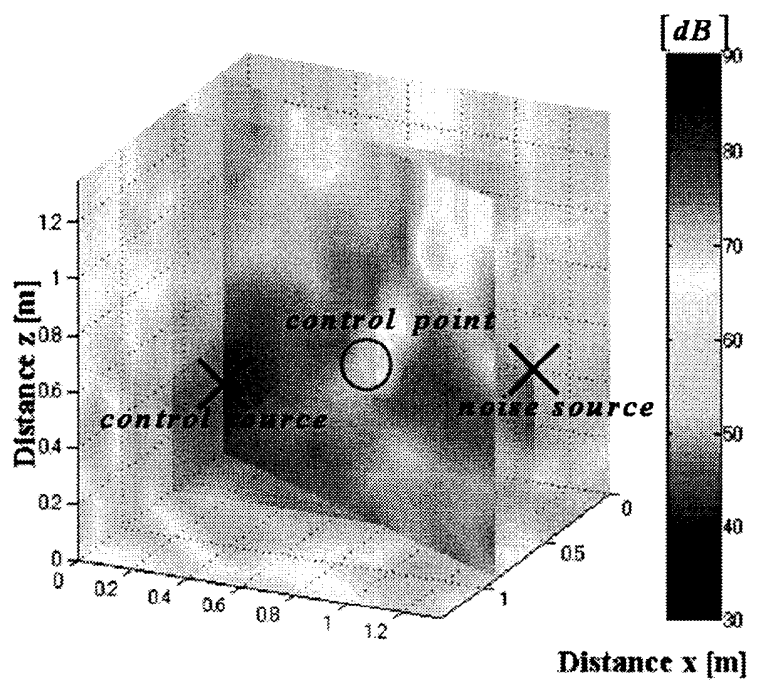

Fig.9 ANC using a voice-coil type speaker

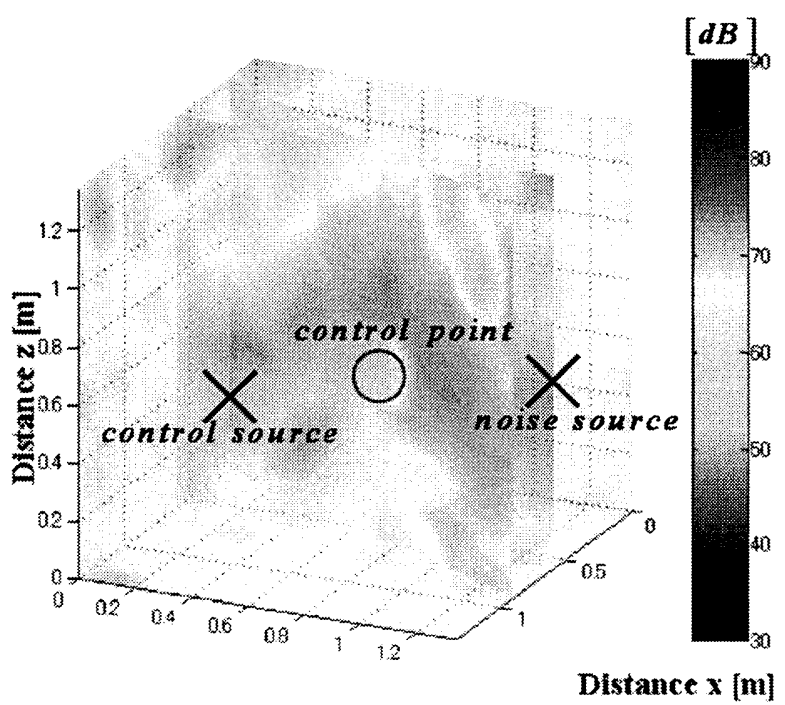

Fig.10 ANC using a matrix phased array speaker 


\section{2 実験結果及び考察}

Fig.9 に示される通常のボイスコイル型スピーカによる ANC と, Fig.10 に示されるマトリックスフェイズドアレイ スピーカによる ANC の実験結果について,それぞれの制御 効果を比較する. ターゲットとした制御点において, 前者 に $15.5[\mathrm{~dB}]$, 後者に $14.5[\mathrm{~dB}]$ の音圧低減が見られ, 両者共 に高い制御効果を確認できた。

次に，ボイスコイル型スピーカとマトリックスフェイズ ドアレイスピーカ用いた ANCにおいて, 制御前(Fig.8)と制 御後(Fig.9,10)の音圧分布をそれぞれ比較する. Fig.9 のボ イスコイル型スピーカを用いた ANC では, 制御前に比べ広 い領域で音圧の悪化が見られるのに対し，Fig.10のマトリ ックスフェイズドアレイスピーカを用いた実験結果では, 制御音源の周囲への影響を小さくできていることが分かる。

最後に, $\mathrm{ANC}$ の実行前後における音場全体の音圧変化 を比較すると，ボイスコイル型スピーカによるAN Cでは 16. $0 \%$ 音圧が上昇したのに対し，マトリックスフェイズドア レイスピーカによるANCでは暗圧上昇を $5.9 \%$ に抑えるこ とができた. したがって，マトリックスフェイズドアレイ スピーカの制御音源としての有用性が示されたといえる.

マトリックスフェイズドアレイスピーカの最適設計を行 い，実際に試作するとともに，ANC実験を行いその有用 性を明らかにした. 以下に本論文により得られた成果を要 約する.

（1）マトリックス状に配列されたフェイズドアレイスピー カのパラメータ (素子数, 素子幅, 素子間隔, ステアリ ング角)の最適な設計方法を明らかにした。

（2）ビームステアリングを二次元領域から三次元領域に拡 大寸ることにより，より自由度の高い ANC が可能になる ことを示した。

（3） $1250 \mathrm{~Hz}$ の騒音に対して，3D ビームステアリングを ANC に応用することで, 制御点の設定を選ばず，かつ周辺に 与える影響が少ない, 高自由度・高効率のアクティブノ イズコントロールシステムが可能になる事を示した。

\section{文献}

(1) P.Lueg, "Process of silencing sound oscillations", US Patent No. 2043416 (1936)

(2) A.C.H. Tan and N. Tanaka, Identifying the attributes of a parametric array loudspeaker, Proceedings of the 11th Asia-Pacific Vibration Conference, 1(2005), pp. 253-259

(3) T.Komatsuzaki, Active Noise Control Using High-directional Parametric Loudspeaker (Experimental Study on Radiated Field, JSME, Vol. 74, No. 737(2008), pp. 75-82.

(4) Y. Aihara and N. Tanaka, Active Noise Control using Strongly High Directive Sound Sources, Transactions of the Japan Society of Mechanical Engineers. C 75(750) pp.357-364 2009/2

(5) M. Tanaka and N. Tanaka, ACTIVE NOISE CONTROLUSING A STEERABLE PARAMETRIC SPEAKER, Department of Aerospace Engineering, (2008)

(6) S.C. Wooh and Y. Shi, "Influence of phased array element size on beam steering behavior", Ultrasonics, 36, (1998), 737-749.
(7) Dan J. Ramsdale and Roger A. Howerton, "Effect of element failure and random errors in amplitude and phase on the sidelobe level attainable with a linear array", J. Acoust. Soc. Am. 68(3), Sept, (1980), 901-906.

（8）山本優一郎，超音波フェイズドアレイの基本原理，溶接 学会誌，第 74 巻，第 4 号(2005), 29-32 